\title{
NURSING STUDENTS READINESS and PERSPECTIVE toward SELF-DIRECTED LEARNING
}

\author{
1 Hoda Reda Abdou,2 Wafaa Fathi Sleem ,3 Nehad Saad EL-Wkeel
}

1,2, 3 Nursing Administration, Faculty of Nursing, Mansoura University, Egypt

\begin{abstract}
Background: One of the most vital attributes for nursing students for long-lasting learning is self-directed learning. Self-directed learning readiness is considered to be highly personalized as well differs significantly between learners in different programs found in higher education so definite abilities, attitudes as well personality characteristics are required for self-directed learning. Aim: This study aims to assess nursing students' readiness and perspective toward self-directed learning. Research design: A descriptive research design was utilized. Methods: The study sample consisted of (300) nursing students from four levels choose by sample size at Faculty of Nursing, Mansoura University. Data were collected by using two tools as: Self-directed learning readiness scale and students' perception about self-directed learning questionnaire. Results: The study finding revealed that three quarter of nursing students were high readiness for selfdirected learning. As well, more than half of nursing students were high perception about self-directed learning. Conclusion: Nursing students' readiness for self-directed learning was high in three quarter of them whereas perception about self-directed learning was high in more than half of them. Recommendation: Encourages policymakers in the college to make policy for self-directed learning in nursing curricula. Promote self-directed learning as a central strategy for developing competency of the nursing students in the clinical practice which emphasis on critical thinking and problem-solving.
\end{abstract}

Keywords: Nursing Students, Perspective, Readiness, Self-Directed Learning. 


\section{Introduction}

Trends of education drifts from artificial to deep learning, from passive to active learning as well from teacherdependent learning to self-directed learning (SDL). Nursing education is well designed to help student's preparation in providing the holistic care to various patients' populations by increasing students' knowledge, and improving their skills in the clinical areas that help them in developing their values professionally and this can be achieved by $\mathrm{SDL}^{(1)}$.

SDL is the individual capability of making a plan and recognize the approaches, resources and tools necessary for an individual's learning. The behaviors and characteristics associated with SDL are correlated to intrinsic motivation, veracity, conscientiousness, persistence and diligence (2). There are a lot of terminologies that have been regarded for describing SDL such as autonomous learning, self-initiated learning, selfteaching, lifelong learning, self-plan learning, independent learning and selfdirection in learning ${ }^{(3)}$.

SDL is different from one person to another as well there are different degrees of learner SDL readiness in higher education. Readiness for SDL also differs significantly among learners in different higher education programs so specific attitudes, capabilities, and personality characteristics are required for SDL ${ }^{(4)}$. SDL readiness is defined as to what extent the learners have many characteristics such as their aptitude as well individuality that are essential for SDL (5). The self-directed learner's control as well are independent to choose what to learn and what is considered to be most important for themselves. In other words, all learners are able to learn but personality differences can affect their educational level including enthusiasm, worth, and honesty for learning ${ }^{(6)}$.

Self-directed learners are critical thinkers who contemplate their learning, personally evaluate their mastery of educational materials and their progress toward goal achievement and are talented to solve problems effectively by successfully using their supra-cognitive capabilities. Self-directed learners are concentrated on the future, they are ready and active contributors in learning chances, and they are innovative and inspired. Furthermore, they are responsible for their own learning automatically through setting distinct learning goals and through the development and use of necessary study skills and self-interest and reassurance to successfully achieve their personal goals (7).

The educator in SDL is not just an authority figure for learners. He / she is sort of provider, mentor, expert, role model, reference and co-learner. The educator is not only a content carrier, but also the manager of the learning process, which aims to enhance learners' learning. Adult educators are alert about their position of strength and know that this strength is dynamic in the relationship with the learners, and that it depends on learning attitudes as well the learners needs ${ }^{(8)}$

SDL may be affected by some factors such as culture and education, environment of learning, learners' learning characteristics and the meaningmaking learning process ${ }^{(9)}$. SDL can lead to more active learning if planned effectively. SDL can help learners to achieve complete understanding instead of duplication of their learning materials 
as well gaining more thoughtful views on issues rather than having a superficial attitude. Furthermore, self-regulating learning allows the learners to be responsible for their learning as well actively participate in the process of learning. Furthermore, improves the learners' positive motivation as well enhances the sense of belonging to learning ${ }^{(\mathbf{1 0})}$.

\section{Significant of the study}

Preparing and maintaining a future workforce able to deal with rapid changes is the aim of higher educational institutions (11) and this can be accomplished through helping learners to be self-directed learners ${ }^{(12)}$. Assessment of learners' readiness for SDL is crucial to reduce incongruence in SDL promoting activities as well learners' capabilities (13). Specifically, in the discipline of nursing, the importance of assessing readiness for SDL is exacerbated by the growing number of evidence available, in addition to the difficulty of patient problems, and the limited time spent on education in the world for three to four years. So, this study aims to assess nursing students' readiness and perspective toward SDL.

\section{Aim of the study}

This study aims to assess nursing students' readiness and perspective toward self-directed learning.

Research questions: -

Q1: What is the level of nursing students' readiness for self-directed learning?

Q2: What is nursing students' perception about self-directed learning?

Q3: What is the relationship between nursing students' readiness and their perception for self-directed learning?

\section{Method}

Research design:

Descriptive research design was utilized.

The study setting :
The present study was done at Faculty of Nursing, Mansoura University.

Participants of the study:

The participants of the study included (300) nursing students from four academic years choose by sample size.

$$
n=\frac{N \times P(1-P)}{\left[(N-1) \times\left(d^{2} / Z^{2}\right)\right]+P(1-P)}
$$

Tool of data collection- :

Two tools were utilized for data collection, namely: Self-Directed Learning Readiness Scale (SDLRS) and Students' perception about Self-Directed Learning Questionnaire.

Tool I: Self-Directed Learning Readiness Scale (SDLRS): This tool adopted from ${ }^{\mathbf{( 1 4 )}}$. It involved two parts as follows:

Part I: Personal characteristics of nursing students: It covered items as gender, age, and academic year.

Part II: Self-Directed Learning Readiness Scale (SDLRS): This tool aimed to assess nursing students' readiness for SDL. It consisted of (40) items categorized into three areas as follow: Self-management (15 items), desire for learning (12 items) and selfcontrol (13 items). Their responses were measured by five-point likert scale as follow ( $1=$ strongly disagree, $2=$ disagree, $3=$ unsure, $4=$ agree and $5=$ strongly agree).

\section{Scoring system:}

Total score on the scale ranged from (40-200). Above 150 score means high degree of SDLR while score below or equal to 150 means low level of SDLR $^{(14)}$.

Tool II: Students' perception about Self-Directed Learning Questionnaire: This tool was developed by the researchers based on literature review ${ }^{(\mathbf{1 5 - 1 6 )}}$. It aimed to assess nursing students' perception about self-directed learning. It consisted of (57 items) 
categorized into six areas as follow: Selfdirected learning concept (9 items), benefits of self-directed learning (12 items), instructors' roles (5 items), selfdirected learning skills for instructor (11 items), students' roles (6 items) and selfdirected learning skills for students (14 items). Their responses were measured by three-point likert scale as follow ( 1 =disagree, $2=$ uncertain and $3=$ agree $)$.

\section{Scoring system:}

The total scores of students' perception about self-directed learning ranged from (57-171). It was categorized into three levels based on cut of point $60 \%$ as:

- Low perception $<60 \%$

- Moderate perception $60 \%-75 \%$

- High perception $>75 \%$

Validity and reliability:

Tools of data collection (I and II) was established for face and content validity via a panel of five experts from different departments at Faculty of Nursing, Mansoura university who reviewed the tools for clarity, understanding, comprehensiveness, relevancy, ease for implementation and applicability and according to their opinions modifications were done.

The study tools were tested to assess reliability via using Cronbach alpha test in Statistical Package for Social Science (SPSS) version 22. Cronbach's Alpha was (0.855-0.894) for SDL readiness scale and students' perception about SDL questionnaire respectively.

\section{Pilot study:}

It was carried on randomly selected $(10 \%)$ of nursing students (30) to test the clarity, feasibility of the questions and the time needed to fill-in questions is from 20-30 minutes. Participants who shared in the pilot study were excluded from the total study sample. Based on the pilot study, necessary modification done by clarification and rewording.

\section{Data collection:}

The questionnaire was handled and filled by the nursing students to elicit their opinion. Collecting data from students by explaining to each student the aim of the study and take his or her acceptance. Filling the questionnaire sheet took from 20-30 minutes. Data collection for nursing students was carried out through distribution of the questionnaire sheet to the participants and handed back to the researcher upon completion. The actual field work of this study was carried out in 3 months from beginning of October to the end of December 2019.

\section{Ethical consideration:}

Ethical approval was attained from the Research Ethics Committee of the Faculty of Nursing - Mansoura University. A formal permission to conduct the study was attained from the Faculty of Nursing - Mansoura University after explanation of the aim of the study. An informed consent was attained from the participants after providing them with complete information about the study. Participants were informed that participation in research is voluntary and they were capable of withdraw from the study without responsibility at any phase. The collected data confidentiality was maintained as well the study sample privacy was guaranteed.

\section{Statistical analysis:}

Data collected, ordered, presented and statistically evaluated using SPSS software (Statistical Package for Social Sciences, Version 22, SPSS Inc., Chicago, IL, USA). Quantitative data, range, mean and standard deviation were calculated. Qualitative data describing the classical data conducted using the 
Chi- -square test $(\chi 2)$ comparing the frequency, percentage or proportion of each category, between the two groups and so on. Student t-test was used to compare the meanings of two sets of parametric data from independent samples. To compare more than two mediums of parametric data, the F-value of the ANOVA test was considered. The correlation between variables was assessed using Pearson correlation coefficient (R). For interpretation of results of tests of significance, significance is adopted at $\mathrm{P}$.

\section{Results:}

Table (1) Illustrated personal characteristics of the studied nursing students. This table shows that more than half of nursing students $(67.3 \%)$ were female, with more than half of them (53.3\%) aged from 18-19 years with mean \pm SD (19.63 \pm 1.37$)$. Concerning academic years, a percentage of $(29.7 \%)$ were in the first academic year, while $(21.0 \%)$ of them in the third academic year.

Figure (1) Demonstrated total self-directed learning readiness mean scores and ranks among the studied nursing students. This figure shows that desire for learning ranked (1) with mean \pm SD (4.02 \pm 0.68$)$, while selfmanagement and self-control ranked (2) with mean \pm SD (3.96 \pm 0.71 - 3.96 \pm 0.67$)$ respectively.

Figure (2) Demonstrated total level of self-directed learning readiness among the studied nursing students. This figure shows that $(70.0 \%)$ of nursing students were high readiness, while
$(30.0 \%)$ of them were low readiness for SDL.

Figure (3) Demonstrated total self-directed learning mean scores and ranks of the studied nursing student's perception. This figure shows that selfdirected learning skills for student ranked (1) with mean $\pm \mathrm{SD}(2.55 \pm 0.46)$, while self-directed learning skills for instructor ranked (5) with mean \pm SD (2.42 \pm 0.52$)$.

Figure (4) Demonstrated total perception level about self-directed learning among the studied nursing students. This figure shows that $(55.7 \%)$ of them were high perception, while $(17.0 \%)$ of them were low perception.

Figure (5) Illustrated correlation between total perception and readiness scores for self-directed learning among the studied nursing students. This figure shows that there was a significant correlation between total perception scores and total readiness scores for selfdirected learning.

Table (2) Illustrated level of total readiness for self-directed learning among the studied nursing students in relation to their personal characteristics. The table shows that there was no significant relation between level of total readiness for self-directed learning and all items of personal characteristics.

Table (3) Illustrated level of perception about self-directed learning among the studied nursing students in relation to their personal characteristics. This table shows that there was no significant relation between level of perception about self-directed learning and all items of personal characteristics. 
1 Hoda Reda Abdou et. al.

Table (1): Personal characteristics of the studied nursing students $(\mathrm{No}=\mathbf{3 0 0})$.

\begin{tabular}{|c|c|c|}
\hline \multirow[t]{2}{*}{ Personal characteristics } & \multicolumn{2}{|c|}{ The studied nursing students $\mathrm{No}=\mathbf{3 0 0}$} \\
\hline & No & $\%$ \\
\hline \multicolumn{3}{|l|}{ Gender: } \\
\hline Male & 98 & 32.7 \\
\hline Female & 202 & 67.3 \\
\hline \multicolumn{3}{|l|}{ Age years: } \\
\hline $18-19$ & 160 & 53.3 \\
\hline $20-21$ & 111 & 37.0 \\
\hline $22-23$ & 29 & 9.7 \\
\hline $\begin{array}{l}\text { Range } \\
\text { Mean } \pm \text { SD }\end{array}$ & \multicolumn{2}{|c|}{$\begin{array}{c}18-23 \\
19.63 \pm 1.37\end{array}$} \\
\hline \multicolumn{3}{|l|}{ Academic year: } \\
\hline First level & 89 & 29.7 \\
\hline Second level & 73 & 24.3 \\
\hline Third level & 63 & 21.0 \\
\hline Fourth level & 75 & 25.0 \\
\hline
\end{tabular}

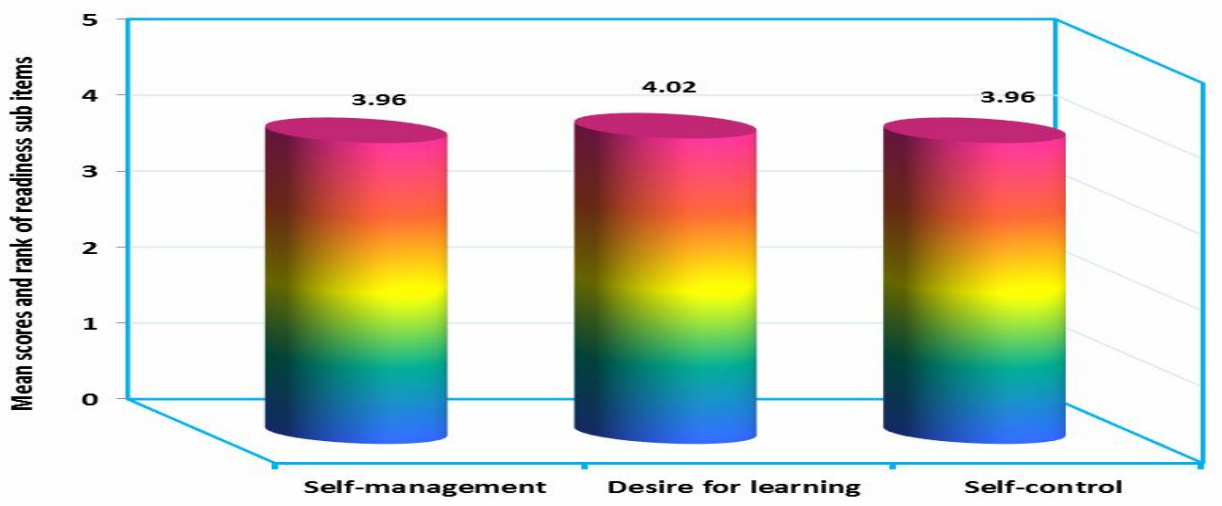

Figure (1): Total self-directed learning readiness mean scores and ranks among the studied nursing students $(\mathbf{N o}=\mathbf{3 0 0})$.

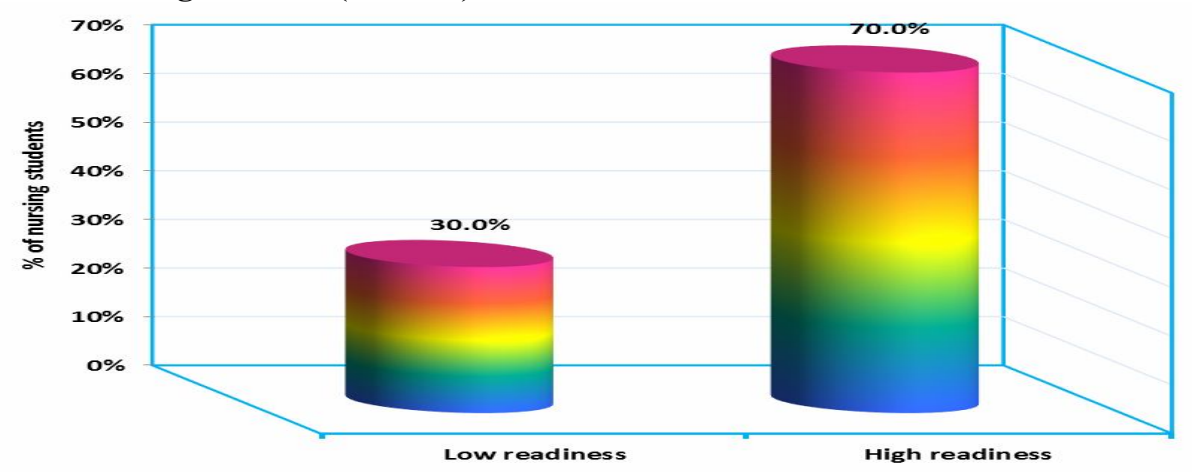

Figure (2): Total level of self-directed learning readiness among the studied nursing students $(\mathbf{N o}=\mathbf{3 0 0})$. 


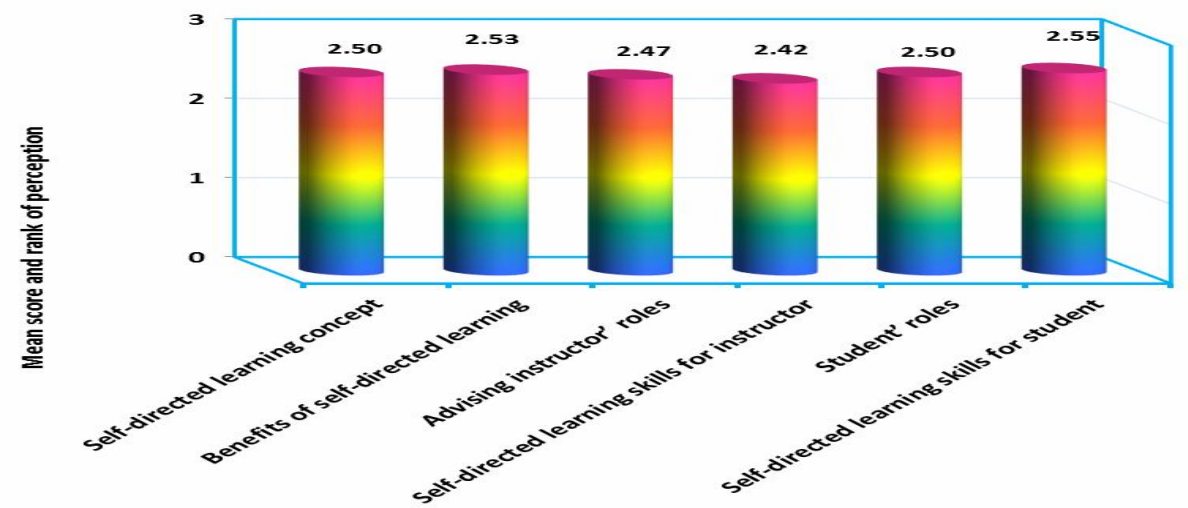

Figure (3) Total self-directed learning mean scores and ranks of the studied nursing student's perception.

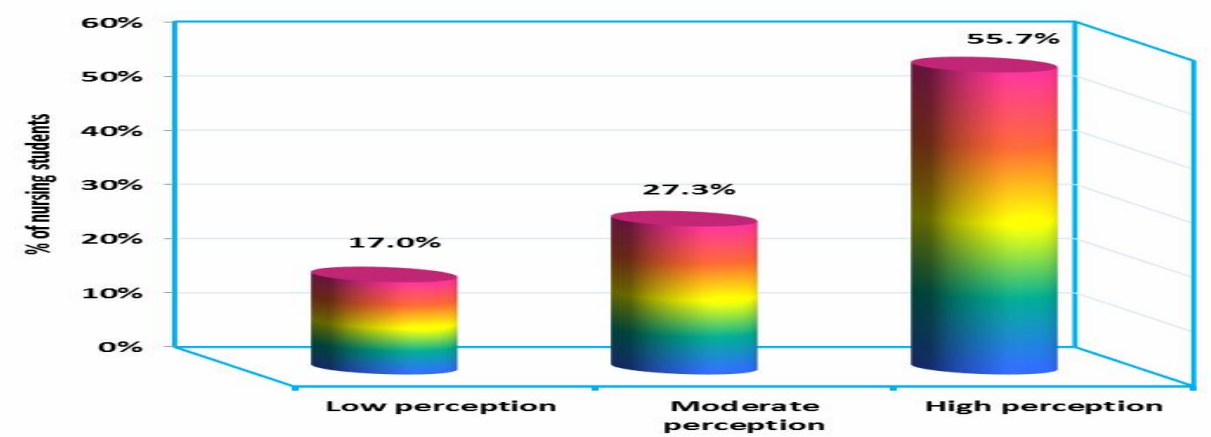

Figure (4): Total perception level about self-directed learning among the studied nursing students $(\mathbf{N o}=\mathbf{3 0 0})$.

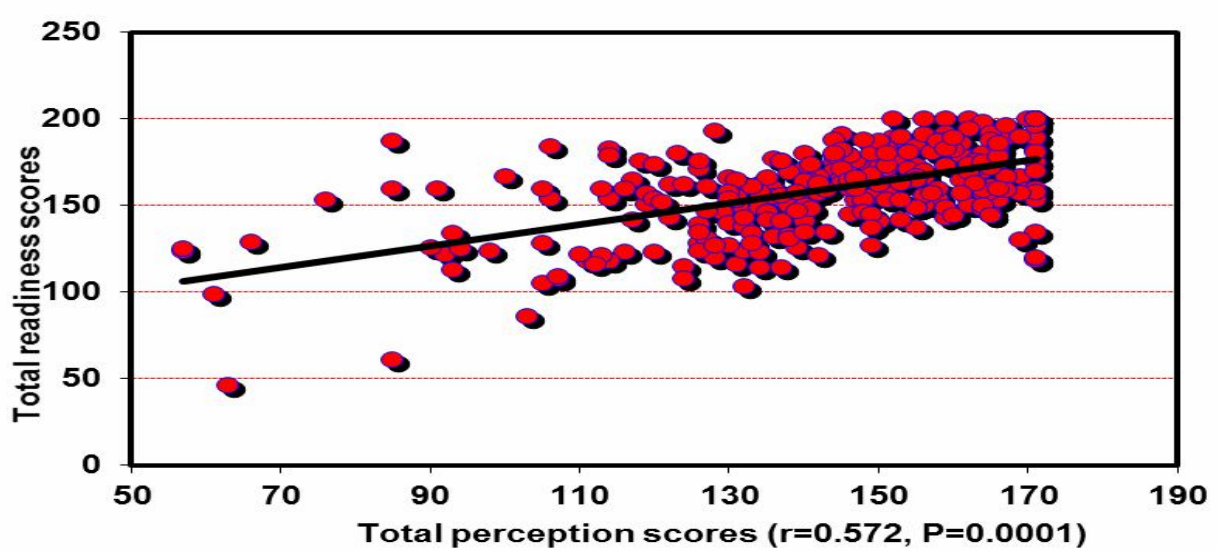

Figure (5): Correlation between total perception scores and total readiness scores for self-directed learning among the studied nursing students $(\mathrm{No}=\mathbf{3 0 0})$. 
SDL keeps them busy because they have to acquire knowledge on their own, as well as use it with their skills to find solutions to their problems related to education and encourage them to continue lifelong learning ${ }^{(\mathbf{1 8})}$.

The lifelong learning approach is basically an internally driven process and cannot be forced. As the success of the SDL process execution depends on the individual's learning preparation, it is important to evaluate the student's preparation in order to promote the student's SDL. This is because SDL is not intended for all students and can cause anxiety and frustration for some students ${ }^{(19) .}$

The present study revealed that less than three quarter of nursing students had high readiness for SDL. This may be due to nursing students encounter with different problems and struggles during their clinical practice and they need developing their knowledge and skill to be more autonomous and confident in selecting their decisions.

The present study consistent with the study of ${ }^{\mathbf{2 0})}$ who found that $60 \%$ of the baccalaureate-nursing student in China reported high level of SDLR. Moreover, (21) found that the nursing students' overall readiness of SDL was considerably high., Also, (19) and (22) whom stated that nursing student have high level of overall SDL mean score. Moreover, (23) declared that the majority of Jordanian and Iranian nursing students had high level of SDLR. Furthermore, pharmacy students showed a high degree of SDL readiness in the University of Maryland in the United State (24). Additionally, (25) found that the nursing students had high SDLR.

In opposite side, ${ }^{(26)}$ showed that only $50 \%$ of the students in Indonesia had high scores for SDLR. Moreover, about $23 \%$ of nursing students in Pakistan were above average on the SDL readiness, whereas $18 \%$ were below average and over $50 \%$ being just average scorers ${ }^{(27)}$.

The present study found that the desire to learn was highest and ranked ${ }^{(1)}$ followed by self-management and selfcontrol. This may be due to the fact that nursing students want to learn and are open to continuous learning when working in a changing and challenging environment. The present study support study done by ${ }^{(25)}$ who found that the highest mean score percentage of readiness was for students' response to desire for learning followed by selfmanagement, while self-control was the lowest. Also, ${ }^{(28)}$ found that the desire for learning was the highest mean score, and the self-management was the lowest mean score.

In contrast, (21) found that the highest mean score percentage of readiness was for self-control dimension followed by desire for learning dimension whereas self-management dimension was the lowest. Moreover, ${ }^{(29)}$ found that students in King Saud University had high score for self-control domain whereas self-management domain was the least score. In the same line, (30) and ${ }^{(21)}$ reported that the high score in student was for self-control domain whereas the least score was for self-management domain.

Regarding nursing students' perception about SDL. The present study found that more than half of nursing students had high perception about SDL. Self-directed learning skills for student item was found the highest and ranked (1), whereas self-directed learning skills for instructor item was the lowest perception and ranked ${ }^{(5)}$. This may be 
due to students need various skills and attitudes for successful independent learning. Also, some students felt unable to approach some instructors and also students are reluctant to approach instructors due to some instructors show little respect for or not caring about students.

The present study agrees with result done by ${ }^{(31)}$ who reported that students' SDL skills means were generally high in the university. Also, ${ }^{(32)}$ mentioned that self-learning skill is considered a very valuable talent in the environment of education necessary for SDL. Moreover, (33) argued that skills required for SDL are crucial to attain significant and lifelong learning outcomes. In the same line, (34) emphasized the role of students' responsibility as a skill required for SDL.

In contrast, (4) suggested that nursing educators must pay attention to learners' independence, particularly during times of knowledge exploration and the technology evolution. Also, ${ }^{(35)}$ stated that teachers need to understand how satisfied students and adult learners are with their past educational experiences to provide better learning experiences for future learners.

The study result revealed that there was a significant correlation between total perception scores and total readiness scores for self-directed learning. This may be due to when nursing students are more aware about SDL, they become more ready to engage in SDL. This is in line with the (26), whom found that students who have a positive perception of self-study have a better tendency to follow studentcentered behaviors. This indicates that student-centered behavior will be better if their perception is better.
The present study found no statistically significant association between personal characteristics and overall self-learning readiness score. This is consistent with a study conducted in the King of Saudi Arabia (22), who found that there was no consistent relationship between demographics and overall self-directed learning readiness score. Additionally, (36) found that demographics were statistically insignificant in relation to the level of self-learning readiness.

In contrast with this finding, ${ }^{(20)}$ in China reported socio demographic characteristics as gender, age, and educational level effect on self-directed learning readiness score. Moreover, (19) investigated the level of self-study readiness of college nursing students and compared this readiness through education years. They stated that nursing students are ready for moderate or high levels of self-study, and this readiness depends on the year of study.

Additionally, (37) and (38) attempted to examine levels of readiness for self-instruction and to compare this preparation in annual education and gender. These studies consistently found that there was a significant difference in the preparation for self-learning in the years of education, but no significant difference between the genders.

The present study revealed that there was no significant relation between level of perception about self-directed learning and all items of personal characteristics. In contrast with this result (39) found that there was a significant increase in SDL perception on comparing students at year-1 with students at year-2. 


\section{Conclusion}

The findings of the present study concluded that three quarter of nursing students were high readiness for SDL. Nursing students strongly agree regarding desire for learning followed by self-management and self-control. More than half of nursing students were high perception about SDL. More than half of nursing students were high level of perception regarding SDL skills for student followed by SDL benefits and SDL concept. There was a significant correlation between total perception scores and total readiness scores for selfdirected learning. There was no statistically significant correlation between personal characteristics with overall score of self-directed learning readiness. As well, there was no significant relation between level of perception about self-directed learning and all items of personal characteristics.

\section{Recommendation}

Based on the findings of this study, the following recommendations are suggested:

- Encourages policymakers in the college to make policy for SDL in nursing curricula.

- Change learning approaches gradually by scheduling time for independent activities within the classroom to increase learner responsibility and choices.

- Promoting self-directed learning as a central strategy for developing competency of the nursing students in the clinical practice which emphasis on critical thinking as well problem-solving.

- Active participation of nursing students in identify their learning needs as well be responsible of learning for their professional and self-development.
Implication for further research:

- Duplicate this study in more than one college and/or university in different regions of Egypt using larger samples size to generalize the findings.

- Further research should follow the development of nursing students' SDL abilities over their academic years as well as their lifelong careers.

Implication for implementation:

- Develop and implement educational booklet about SDL at faculty of Nursing, Mansoura University.

- Print handouts of the booklet to be available for nursing students and academic staff to be aware of their roles in SDL.

\section{References}

[1] Gagne,S. (2017). Improving Adult Learners' Experience with Continuing Professional Education :A Transformational Path to Andragogy. The Organizational Improvement Plan at Western University, 23. Retrieved from https://ir.lib.uwo.ca/oip/23

[2] Caruso, S. J. (2018). Toward understanding the role of Web 2.0 technology in self-directed learning and job performance. Contemporary Issues in Education Research (CIER), 11(3), 89-98.

[3] Chang, S. M. (2012). The Effect of Specific Goals on EFL Students' Self-Efficacy and Performance On Vocabulary Learning. NCUE Journal of Humanities 5(1) : 53-74.

[4] Alotaibi, K. N. (2016). The Learning Environment as a Mediating Variable Between SelfDirected Learning Readiness and Academic Performance of a Sample of Saudi Nursing and 
1 Hoda Reda Abdou et. al.

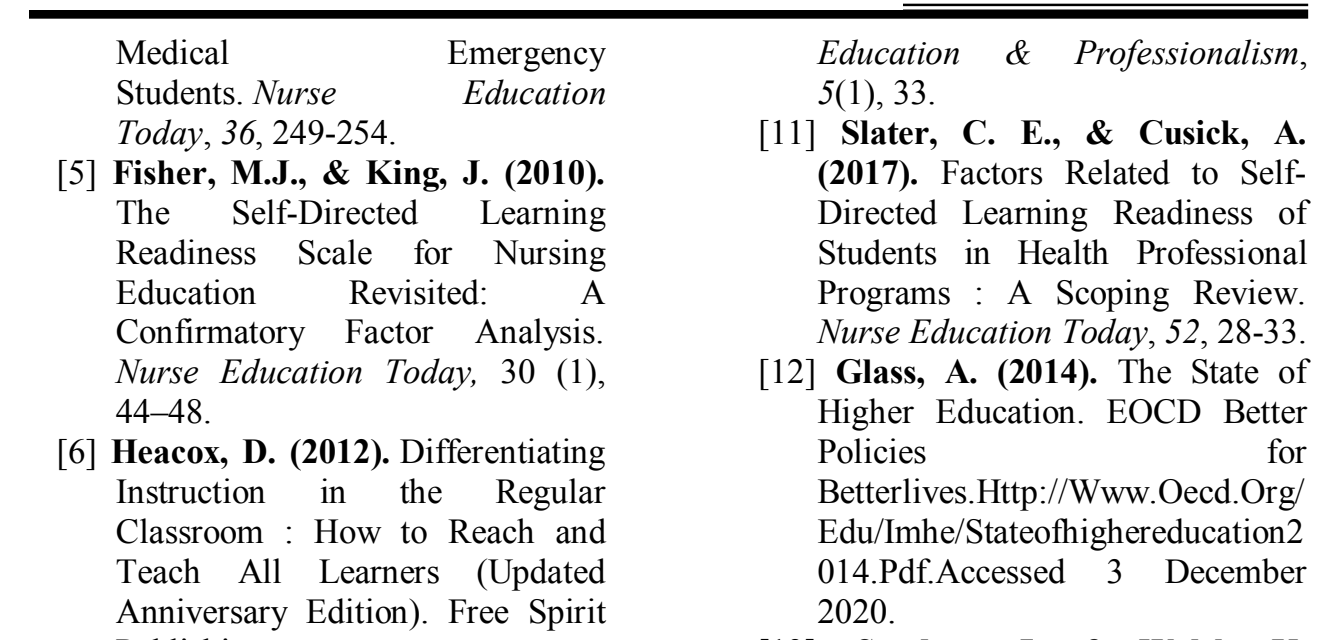
Publishing.

[7] De Bruin, K., \& De Bruin, G. P. (2011). Development of The Learner Self-Directedness In the Workplace Scale. SA Journal of Industrial Psychology, 37(1), 0110.

[8] Nagara, C. K. N. (2020). Pedandragogy: Promoting Effective Learning Environments and Self-Efficacy in Adult Learners With Andragogy and Pedagogy (Doctoral Dissertation, Indiana University of Pennsylvania).

[9] Merriam, S. B. (2018). Adult Learning Theory : Evolution And Future Directions. in Contemporary Theories of Learning (Pp. 83-96). Routledge. Retrived from https://www.taylorfrancis.com/cha pters/adult-learning-theory-sharanmerriam/e/10.4324/978131514727 7-6

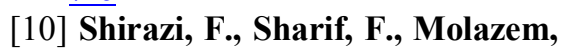
Z., \& Alborzi, M. (2017). Dynamics of Self-Directed Learning In M. Sc. Nursing Students: a Qualitative Research. Journal of Advances in Medical

[13]. Sandars, J., \& Walsh, K. (2016). Self-directed learning. Education for Primary Care, 27(2), 151-152.

[14] Fisher, M., King, J., \&Tague, G. (2001). Development Of A SelfDirected Learning Readiness Scale For Nursing Education. Nurse Education Today, 21(7), 516-525.

[15] Payne, S. S., Rocks, J., \& Schaffner, B. (2014). SelfDirection In Learning And Academic Motivation Development In Undergraduate Health Profession Students. International Journal Of SelfDirected Learning, 11(1), 41-51.

[16] Falk, K., Falk, H., \& Ung, E. J. (2016). When Practice Precedes Theory-A Mixed Methods Evaluation of Students' Learning Experiences In An Undergraduate Study Program in Nursing. Nurse Education In Practice, 16(1), 1419.

[17] Jaleel, S., \& OM, A. (2017). A Study on the Relationship between Self Directed Learning and Achievement in Information Technology of Students at Secondary Level. Universal 
Journal of Educational Research, 5(10), 1849-1852.

[18] Hill, M., Peters, M., Salvaggio, M., Vinnedge, J., \& Darden, A. (2020). Implementation And Evaluation of A Self-Directed Learning Activity for First-Year Medical Students. Medical Education Online, 25(1), 1717780.

[19] Klunklin, A., Viseskul, N., Sripusanapan, A., \& Turale, S. (2010). Readiness for Self $\square$ Directed Learning Among Nursing Students in Thailand. Nursing \& Health Sciences, 12(2), 177-181.

[20] Yuan, H. B., Williams, B. A., Fang, J. B., \& Pang, D. (2012). Chinese Baccalaureate Nursing Students' Readiness for SelfDirected Learning. Nurse Education Today, 32(4), 427-431.

[21] El Seesy, N., Sofar, S. M., Ali, J., \& Al-Battawi, I. (2017). SelfDirected Learning Readiness among Nursing Students at King abdulaziz university, Saudi Arabia., 6 (6), 14-24.

[22] El-Gilany, A. H., \& Abusaad, F. E. S. (2013). Self-Directed Learning Readiness and Learning Styles among Saudi Undergraduate Nursing Students. Nurse Education Today, 33(9), 1040-1044.

[23] Safavi, M., Shooshtari, S., Mahmoodi, M., \& Yarmohammadian, M. H. (2010). Self-Directed Learning Readiness and Learning Styles among Nursing Students of Isfahan University of Medical Sciences. Iranian Journal of Medical Education, 10(1), 27-36.

[24] Huynh, D., Haines, S. T., Plaza, C. M., Sturpe, D. A., Williams,
G., De Bittner, M. A. R., \& Roffman, D. S. (2009). The Impact Of Advanced Pharmacy Practice Experiences on Students' Readiness for Self-Directed Learning. American Journal of Pharmaceutical Education, 73(4), 65.

[25] Örs, M. (2018). The SelfDirected Learning Readiness Level of the Undergraduate Students of Midwife and Nurse in Terms of Sustainability in Nursing and Midwifery Education. Sustainability, 10(10), 3574.

[26] Lestari, E., \& Widjajakusumah, D. (2009). Students' Self-Directed Learning Readiness, Perception toward Student-Centered Learning and Predisposition towards StudentCentered Behavior. South East Asian Journal of Medical Education, 3(1), 52-56.

[27] Bruce, J. C., Lack, M., Bomvana, N. M., \& QamataMtshali, N. (2018). ProblemBased Learning : Nursing Students' Attitude, Self-Reported Competence, Tutorial Performance and Self-Directed Learning Readiness. Journal of Nursing Education And Practice, 8(10), 1119.

[28] Yang, G. F., \& Jiang, X. Y. (2014). Self-Directed Learning Readiness and Nursing Competency Among Undergraduate Nursing Students in Fujian Province of China. International Journal of Nursing Sciences, 1(3), 255-259.

[29] Soliman, M., \& Al-Shaikh, G. (2015). Readiness for SelfDirected Learning among First 
Year Saudi Medical Students: a Descriptive Study. Pakistan Journal of Medical Sciences, 31(4), 799.

[30] Alkorashy, H. A. E., \& Assi, N. E. A. (2016). Readiness for selfdirected learning among bachelor nursing students in Saudi Arabia: A Survey-Based Study. International Journal of Nursing Education and Research, 4(2), 187-194.

[31] Tekkol, İ. A., \& Demirel, M. (2018). An Investigation of SelfDirected Learning Skills of Undergraduate Students. Frontiers in Psychology, 9, 2324.

[32] Şenyuva, E., \& Kaya, H. (2014). Effect Self-Directed Learning Readiness of Nursing Students of the Web Based Learning. Procedia-Social And Behavioral Sciences, 152, 386392.

[33] Nantz, K., \& Klaf, S. (2012, June). Putting the Spotlight on Learning: Cultivating SelfDirected Learners by Design. in Voordrag Aangebied by Die 9th Annual Teaching Professor Conference, Washington, DC.

[34] English, M. C., \& Kitsantas, A. (2013). Supporting Student SelfRegulated Learning in Problemand Project-Based Learning. Interdisciplinary
Journal of Problem-Based Learning, 7(2), 6.

[35] Pezeshkirad, G., Golshiri, E. Z., \& Chizari, M. (2009). Learner Satisfaction with Pomegranate Production Extension-Education Courses in Yazd Province, Iran. JAST. 11 (1), 49-55.

[36] Mohoaduba, P. L. (2018). Selfdirected learning readiness of nursing students in their fourth year of study in a public nursing college in Johannesburg, Gauteng Province, South Africa (Doctoral dissertation, Stellenbosch: Stellenbosch University).

[37] Bodkyn, C., \& Stevens, F. (2015). Self-directed learning, intrinsic motivation and student performance. The Caribbean Teaching Scholar, 5(2),79-93.

[38] Razali, A. B., Xuan, L. Y., \& Samad, A. A. (2018). SelfDirected Learning Readiness (SDLR) among foundation students from high and low proficiency levels to learn English language. Malaysian Journal of Learning and Instruction, 15(2), 55.

[39] Kidane, H. H., Roebertsen, H., \& Van der Vleuten, C. P. (2020). Students' perceptions towards selfdirected learning in Ethiopian medical schools with new innovative curriculum: a mixedmethod 